\title{
AIDS related eye disease in Burundi, Africa
}

Isabelle Cochereau, Najoua Mlika-Cabanne, Philippe Godinaud, Théodore Niyongabo, Bernard Poste, Athanase Ngayiragije, Marie-Christine Dazza, Pierre Aubry, Bernard Larouzé

\begin{abstract}
Aims-To determine the prevalence of ocular manifestations in AIDS patients hospitalised in Bujumbura, Burundi, according to their CD4+ lymphocyte count, serological status for CMV and VZV, and general health status.

Methods-Prospective study of 154 consecutive patients who underwent general and ophthalmological examinations, including dilated fundus examination. AIDS was diagnosed on the basis of Bangui criteria and HIV-1 seropositivity. CD4+ lymphocyte counts were determined by the Capcellia method. CMV and VZV antibodies were detected with ELISA methods.

Results-The mean age was 37 (SD 9) years and $65 \%$ of the patients were male. Active tuberculosis was the most frequent underlying disease (61\%). Almost all the patients $(99 \%)$ were seropositive for CMV and VZV. Among the 115 patients for whom CD4+ lymphocyte counts were available, $86(75 \%)$ had more than 100 cells $\times 10^{6} / 1$. Ocular involvement comprised 16 cases of microangiopathy, six of opalescence of the anterior chamber, five of retinal perivasculitis, two of zoster ophthalmicus, two of viral retinitis, and one of opalescence of the vitreous.

Conclusion-In Africa, the prevalence of ocular involvement in HIV infection is far lower than in Europe and the United States, possibly because most African patients die before ocular opportunistic infections occur.
\end{abstract}

(Br F Ophthalmol 1999;83:339-342)

IMEA/INSERM U13, Hôpital Bichat, Paris, France

I Cochereau

N Mlika-Cabanne

M-C Dazza

B Larouzé

Centre

Hospitalo-Universitaire

de Kamenge,

Bujumbura, Burundi

P Godinaud

T Niyongabo

B Poste

A Ngayiragije

P Aubry

Correspondence to:

Dr Isabelle Cochereau,

Service d'Ophtalmologie,

Hôpital Bichat, 46, rue Henri

Huchard, 75018 Paris,

France.

Accepted for publication 30 September 1998 ocular complications of hu deficiency virus (HIV) infection have been widely documented in North America and Europe. Cytomegalovirus (CMV) retinitis is a leading cause of blindness among HIV infected patients in industrialised countries. ${ }^{1-4}$ The few published studies of HIV infected patients in Africa show a different pattern of ocular involvement; in particular, CMV retinitis appears to be uncommon in Africa. ${ }^{5-11}$

In Burundi, a country located in central Africa, the HIV seroprevalence rate is high and AIDS is a major health problem. We conducted a prospective study in Bujumbura, the capital, to assess the prevalence of ocular complications in AIDS patients according to clinical status and the CD4+ lymphocyte count.

\section{Patients and methods}

During a 3 month period, consecutive patients with AIDS admitted to the Department of
Internal Medicine of Kamenge University Hospital, Bujumbura, Burundi, underwent a complete ophthalmological examination and a general physical examination. AIDS was diagnosed on the basis of the Bangui definition ${ }^{12}$ (Table 1) and HIV-1 seropositivity. Antibodies to HIV-1 were routinely detected by using an enzyme linked immunosorbent assay (ELISA) (Elavia, Diagnostics Pasteur, Marnes-laCoquette, France) with western blot confirmation (New Lav-blot, Diagnostics Pasteur, Marnes-la-Coquette, France). CMV and varicella zoster virus (VZV) antibodies were routinely detected by using ELISA methods (Enzygnost CMV, Enzygnost VZV, Abbott Laboratories, Chicago, IL, USA).

The CD4+ lymphocyte count was determined by means of the Capcellia ELISA method (Diagnostics Pasteur, Marnes-laCoquette, France) which assays cell bound soluble CD4 receptors. ${ }^{13}$ The results were converted into absolute CD4+ lymphocyte counts by using conversion tables and are expressed as cells $\times 10^{6} / 1$.

Other investigations, performed when necessary, included chest radiography, sputum examination for acid fast bacilli, Pneumocystis carinii, Toxoplasma gondii, and Cryptococcus neoformans, lumbar puncture, stool parasitological examination, and thick smear for malaria. The panel of available tests was limited but included those required for the diagnosis of the most common opportunistic agents found in African AIDS patients.

The ophthalmological examination consisted of inspecting the external eye, motility testing, visual acuity determination, complete slit lamp examination including applanation tonometry and dilated fundus examination (Goldmann lens).

Data were recorded on individual case report forms by the investigators at Kamenge Hospital, and were analysed at IMEA/ INSERM U13 using EPI-INFO software.

Table 1 Clinical definition of AIDS according to the Bangui criteria ${ }^{12}$

Major criteria:

- Loss of more than $10 \%$ of body weight

- Diarrhoea for more than 1 month

- Permanent or discontinue fever for more than 1 month

Minor criteria:

- Cough for more than 1 month

- Generalised pruriginous dermatitis

- Relapsing herpes zoster ophthalmicus

- Oropharyngal candidiasis

- Generalised or chronic herpes

- Generalised lymphadenopathy

AIDS = presence, in patients without cancer or malnutrition, of

- at least two major criteria and one minor criterion

- and/or aggressive Kaposi's sarcoma

- and/or proved cryptococcal meningitis 
Table 2 CD4+ lymphocyte counts in 115 African AIDS patients

\begin{tabular}{llc}
\hline & \multicolumn{2}{c}{ Number of patients } \\
\cline { 2 - 3 } CD4+ lymphocyte count $\left(\right.$ cells $\left.\times 10^{6} / l\right)$ & $n$ & $(\%)$ \\
\hline$>200$ & 59 & $(51)$ \\
$(100-200)$ & 27 & $(24)$ \\
$(50-100)$ & 12 & $(10)$ \\
$<50$ & 17 & $(15)$ \\
\hline
\end{tabular}

Table 3 General manifestations (symptoms, opportunistic infections, cancers) in 154 African AIDS patients

\begin{tabular}{lll}
\hline & \multicolumn{2}{l}{ Prevalence } \\
\cline { 2 - 3 } Manifestations & $n$ & $(\%)$ \\
\hline Tuberculosis & 94 & $(61)$ \\
Oral candidiasis & 49 & $(32)$ \\
Cryptococcal meningitis & 23 & $(15)$ \\
Recurrent zoster dermatitis & 22 & $(14)$ \\
Bacterial pneumonia & 16 & $(10)$ \\
Kaposi's sarcoma & 4 & $(3)$ \\
Neuropathy & 4 & $(3)$ \\
Intestinal isosporosis & 2 & \\
Hairy leucoplasia & 2 & \\
Pneumocystis carinii pneumonia & 1 & \\
Recurrent herpes simplex & 1 & \\
\hline
\end{tabular}

Table 4 Ocular findings related to HIV disease in 154 African AIDS patients

\begin{tabular}{lcc}
\hline & \multicolumn{2}{c}{ Number of patients } \\
\cline { 2 - 3 } Ocular involvement & $n$ & $(\%)$ \\
\hline Herpes zoster ophthalmicus & 2 & $(1)$ \\
Opalescence of the anterior chamber & 6 & $(4)$ \\
Opalescence of the vitreous & 1 & \\
Microangiopathy & 16 & $(10)$ \\
Vascular sheating & 5 & $(3)$ \\
Viral retinitis & 2 & $(1)$ \\
\hline
\end{tabular}

Results

A total of 154 patients were enrolled. The male:female sex ratio was 1.85 and the mean age 37 (SD 9) years.

The CD4+ lymphocyte count was not determined in 39 cases because of a transient technical failure. Among the remaining 115 patients, $86(75 \%)$ had more than 100 CD4+ lymphocytes $\times 10^{6} / 1$ (Table 2 ).

The patients were admitted for different reasons (Table 3). Active tuberculosis was found in $61 \%$ of patients. The other conditions were less common and included oral candidiasis in $32 \%$, cryptococcal meningitis in $15 \%$, recurrent herpes zoster infections in $14 \%$, and bacterial pneumonia in $10 \%$.

Antibodies to CMV and VZV were found in $152(99 \%)$ of the 154 patients. Two patients were CMV seropositive and VZV seronegative. Two other patients were CMV seronegative and VZV seropositive.

Few of the patients had ocular symptoms. Visual acuity was $20 / 30$ or better in $80 \%$ of the eyes. Poor vision was due to common problems unrelated to HIV infection.

Two patients had herpes zoster ophthalmicus (Table 4). Examination of the orbit and oculomotility was normal in all the patients. None of the four patients with multifocal Kaposi's sarcoma had involvement of the eyelids or conjunctiva.

The anterior segment was affected in six patients, who had anterior inflammation de- fined by opalescence in the anterior chamber and keratic precipitates. In one patient it was related to lens trauma; no cause was found in the other five cases, but HSV or VZV infections could not be ruled out.

Involvement of the posterior segment was more frequent (Table 4). Microangiopathy was found in $16(10 \%)$ of the patients. It consisted of cotton wool spots alone in 11 patients and cotton wool spots with haemorrhage in five patients. The distribution of the patients with microangiopathy according to the CD4+ lymphocyte count was as follows: seven $(8 \%)$ of the 86 patients had more than 100 cells $\times 10^{6} / 1$, two $(17 \%)$ of the 12 patients had between 50 and 100 cells $\times 10^{6} / 1$, and four $(24 \%)$ of the 17 patients had fewer than 50 cells $\times 10^{6} / 1$. Peripheral vascular sheathing was found in five patients $(3 \%)$. One patient had slight vitritis, associated with microangiopathy and retinal perivasculitis. Only two patients had clinically diagnosed CMV retinitis with white retinal necrosis and haemorrhages, slight opalescence of the anterior chamber and vitreous, and slow progression. The CD4+ lymphocyte count was unknown in one patient and $200 \times 10^{6} / 1$ in the other. No choroidal lesions related to tuberculosis were found and no cases of ocular toxoplasmosis were diagnosed.

\section{Discussion}

AIDS is a major health problem in Africa. The clinical profile of HIV disease appears to be different in Africa from that in North America and Europe. In Africa, patients with AIDS die mainly from tuberculosis, bacteraemia, cerebral toxoplasmosis, cryptococcosis, invasive salmonellosis, and recurrent bacterial pneumonia. ${ }^{14-17}$ Pneumocystis carinii pneumonia, CMV infection, and Kaposi's sarcoma seem to be uncommon. This difference might be explained by factors such as misdiagnosis due to a lack of test facilities, a different microbiological environment, poor conditions of hygiene, and the lack of effective therapies. In Burundi the HIV seroprevalence rate is $11.3 \%$ in Bujumbura and $0.7 \%$ in rural areas.

The general clinical characteristics of our population are compatible with those of previous African series. ${ }^{17} 18$ In particular, the most frequent opportunistic infection was tuberculosis.

We assessed the prevalence rather than the incidence of ocular involvement in hospitalised AIDS patients because of the difficulty of monitoring patients in Africa. Patients who come to the hospital are those who can afford to do so. The short term mortality rate among hospitalised African AIDS patients is high. ${ }^{15} 17$ Patients who discharge themselves usually die at home without returning to the hospital.

The pattern of ocular involvement in AIDS patients in Africa also seems to be different from that in industrialised countries, ${ }^{5-11}$ where infectious retinitis is common and can lead to blindness.

In this study, ophthalmological abnormalities were found in $21 \%$ of the patients, few of whom complained of ocular symptoms and most of whom had satisfactory visual acuity. These oph- 
Table 5 Ocular findings in African AIDS patients (previous reports and our series)

\begin{tabular}{llllll}
\hline & $\begin{array}{l}\text { Kestelyn, } \\
\text { Rwanda }\end{array}$ & $\begin{array}{l}\text { Kawe, } \\
\text { Zaire }\end{array}$ & $\begin{array}{l}\text { Auzemery, } \\
\text { central Africa }\end{array}$ & $\begin{array}{l}\text { Lewallen, } \\
\text { Malawi }\end{array}$ & $\begin{array}{l}\text { Cochereau, } \\
\text { Burundi }\end{array}$ \\
\hline No of patients & 20 & 45 & 77 & 99 & 154 \\
Cotton wool spots & $30 \%$ & $42 \%$ & $15 \%$ & $13 \%$ & $10 \%$ \\
Haemorrhage & $10 \%$ & $24 \%$ & $12 \%$ & $3 \%$ & $3 \%$ \\
Perivasculitis & $15 \%$ & $2 \%$ & $2 \%$ & $1 \%$ & $3 \%$ \\
CMV retinitis & $0 \%$ & $4 \%$ & $2 \%$ & $1 \%$ & $1 \%$ \\
Kaposi's sarcoma & $0 \%$ & $9 \%$ & $4 \%$ & ND & $0 \%$ \\
Zoster ophthalmicus & $0 \%$ & $18 \%$ & $1 \%$ & ND & $1 \%$ \\
Anterior uveitis & ND & ND & ND & $2 \%$ & $4 \%$ \\
\hline
\end{tabular}

$\mathrm{ND}=$ not determined.

thalmological findings are consistent with previously published series (Table 5), such as 99 AIDS patients in Malawi admitted to the general medicine and tuberculosis wards. ${ }^{11}$

Herpes zoster ophthalmicus was uncommon, even though almost all the patients were VZV seropositive and 22 had a history of mucocutaneous herpes zoster. This low prevalence of zoster ophthalmicus may be related to the clinical status of our patients. Indeed, zoster ophthalmicus usually occurs in earlier stages of HIV disease in otherwise healthy controls. ${ }^{9}$ In addition, these patients are not hospitalised in Burundi as no treatment is available.

Kaposi's sarcoma, which is endemic in Africa, is not as frequent in African AIDS patients as in North American and European AIDS patients. Conjunctival squamous cell carcinoma has been found in HIV infected patients in Uganda. ${ }^{19}$

Anterior uveitis might be due to multiple causes, especially HSV, VZV and tuberculosis.

The most frequent eye problem was HIV related microvasculopathy, which was present in $10 \%$ of the patients. Its frequency increases with the stage of HIV disease. Previous African studies have given similar rates, ranging from $13 \%$ to $42 \% .^{5-7}{ }^{11}$ These rates are lower than those found in industrialised countries. ${ }^{1420} \mathrm{In}$ this study, peripheral vascular sheathing was found in only $3 \%$ of the patients. In other series it has been found to occur at an early stage of HIV disease, and mainly in children.

Only two of our 154 African patients (1\%) had CMV retinitis, a frequency similar to that in previous African series (Table 5). The frequency of CMV retinitis is surprisingly low given that CMV infection is highly endemic in these populations, ${ }^{21-24}$ as confirmed by the $99 \%$ seroprevalence of CMV in our series. This contrasts with the situation in industrialised countries, where CMV retinitis is frequent, usually occurring when the CD4+ lymphocyte count is below 50 cells $\times 10^{6} / 1 .^{25}{ }^{26}$ Before the use of protease inhibitors, a retrospective study performed in Illinois (United States), showed that the percentage of patients developing CMV retinitis at 27 months with baseline CD4+ lymphocyte counts of more than 100 cells $\times 10^{6} / 1$ was $14.7 \%$, compared with $41.9 \%$ in patients with baseline CD4+ lymphocyte counts of less than 50 cells $\times 10^{6} / 1{ }^{25}$ Another study from California showed that none of 45 patients with CD4+ lymphocytes counts of 50 $\times 10^{6} / 1$ or more had CMV retinitis, whereas 26 of 87 patients with CD4+ lymphocyte counts below $50 \times 10^{6} / 1$ had CMV retinitis. ${ }^{26}$ One of our patients with CMV retinitis had a count of 200 CD $4+$ cells $\times 10^{6} / 1$, as in a previous report. ${ }^{27}$ In a study of African patients with CMV infection, the CD4+ lymphocyte count, assessed by flow cytometry, ranged from 1 to 341 cells $\times 10^{6} / 1^{17}$

The low frequency of ocular abnormalities, especially CMV retinitis, in African AIDS patients could be due to racial or ill defined environmental factors, but also to less severe immunosuppression. Indeed, $75 \%$ of our patients had more than $100 \mathrm{CD} 4+$ lymphocytes $\times 10^{6} / 1$. In Africa most patients die before reaching the later stages of immunosuppression. In an necropsy study performed in Abidjan, the median CD4+ lymphocyte count of 133 HIV-1 infected patients who died of AIDS was $88 \times 10^{6} / 1 .{ }^{17}$ The main cause of death among AIDS patients in sub-Saharan Africa is tuberculosis ${ }^{15}{ }^{17}$ which appears at a relatively early stage of HIV infection. ${ }^{18}{ }^{28}{ }^{29}$ Tuberculosis is very frequent in Burundi. ${ }^{30}$

In contrast with North America and Europe, sight threatening infections are uncommon in AIDS patients in Burundi, probably because they die before reaching the degree of immunosuppression at which clinically apparent eye disease generally occurs. In particular, it is likely that most African AIDS patients will die before developing overt CMV retinitis.

This work was supported in part by a grant from the Agence Nationale de Recherches sur le Sida no 93-002.

1 Holland GN, Pepose JA, Pettit TH, et al. Acquired immune deficiency syndrome: ocular manifestations. Ophthalmology 983;90:859-72.

2 Jabs DA, Green WR, Fox R, et al. Ocular manifestations of acquired immune deficiency syndrome. Ophthalmology 1989;96:1092-9.

3 Palestine AG, Rodrigues MM, Macher AM, et al. Ophthalmic involvement in acquired immunodeficiency syndrome. Ophthalmology 1984;91:1092-9.

4 Pepose JS, Holland GN, Nestor MS, et al. Acquired immune deficiency syndrome: pathogenic mechanisms of ocular disease. Ophthalmology 1985;92:472-84.

5 Auzemery A, Queguiner P, Georges AJ, et al. Manifestations ophtalmologiques du syndrome d'immuno-déficience acquise (SIDA) en Afrique Centrale. Médecine Tropicale 1990;50:441-3.

6 Kawe LW, Renard G, LeHoang P, et al. Manifestations ophtalmologiques du SIDA en milieu africain. A propos de 45 cas. F Fr Ophtalmol 1990;13:199-204.

7 Kestelyn P, Van de Perre P, Rouvroy D, et al. A prospective study of the ophthalmologic findings in the acquired immune deficiency syndrome in Africa. Am $\mathcal{F}$ Ophthalmol 1985;100:230-8. Kestelyn P, Lepage P, Van de Perre P. Perivasculitis of the
retinal vessels as an important sign in children with AIDSrelated complex. Am f Ophthalmol 1985;100:614-15.

9 Kestelyn P, Stevens AM, Bakkers E, et al. Severe herpes zoster ophthalmicus in young African adults: a marker for Kestelyn P, Taelman H, Bogaerts J, et al. Ophthalmic manifestations of infections with Cryptococcus neoformans in patients with the acquired immunodeficiency syndrome. Am $\mathcal{F}$ Ophthalmol 1993;116:721-7.

11 Lewallen S. Kumwenda J, Maher D, et al. Retinal findings in Lewallen S. Kumwenda J, Maher D, et al. Retinal findings in
Malawian patients with AIDS. Br f Ophthalmol 1994;78: $757-9$

12 World Health Organisation. Workshop on AIDS in Central Bangui. Oct 22-24 1985, WHO CDS SIDA 85-1.

13 Carriere D, Fontaine C, Berthier AM, et al. Two-site enzyme immunoassay of CD4 and CD8 molecules on the surface of T lymphocyte from healthy subjects and HIV-1 infected patients. Clin Chemother 1994;40:30-7.

14 Aubry P, Kamanfu G, Niyongabo Th, et al. Infections opportunistes au cours du SIDA chez l'adulte africain. Médecine et Armées 1992;20:177-83.

15 Colebunders RL, Latif AS. Natural history and clinical presentation of HIV-1 infection in adults. AIDS 1991; 5(Suppl 1): 103-12.

16 Gilks CF. The clinical challenge of the HIV epidemic in the developing world. Lancet 1993;342:1037-9.

17 Lucas SB, Hounnou A, Peacok C, et al. The mortality and pathology of HIV infection in a West African city. AIDS 1993;7:1569-79. 
18 Mukadi Y, Perriëns JH, St Louis ME, et al. Spectrum of immunodeficiency in HIV-1 infected patients with pulmoimmunodeficiency in HIV-1 infected patients with

19 Ateenyi-Agaba C. Conjunctival squamous-cell carcinoma associated with HIV infection in Kampala, Uganda. Lance 1995;345:695-6.

20 DeCock KM, Soro B, Coulibaly IM, et al. Tuberculosis and HIV infection in sub-Saharan Africa. FAMA 1992;268 $1581-7$

21 Bello C, Whittle H. Cytomegalovirus in Gambian mothers and their babies. F Clin Pathol 1991;44:366-9.

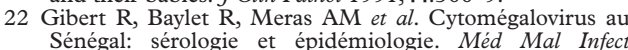
1982;12:62-5.

23 Olaleye OD, Omilabu SA, Baba SS. Cytomegalovirus infection among tuberculosis patients in a chest hospital in Nigeria. Comp Immunol Microbiol Infect Dis 1990;13:101-6.

24 Quinn TC, Piot P, McCormick JB, et al. Serologic and immunologic studies in patients with AIDS in North Ammerica and Africa. $\mathcal{F A M A} 1987 ; 257: 2617-21$.

25 Kuppermann BD, Petty JG, Richman DD, et al. Correlation between CD4+ counts and prevalence of cytomegalovirus retinitis and human immunodeficiency virus-related noninfectious retinal vasculopathy in patients with acquired immunodeficiency syndrome. Am $\mathcal{f} O p h t h a t m o l$ 575-82.

26 Pertel P, Hirschtick R, Phair J, et al. Risk of developing cytomegalovirus retinitis in persons infected with the human imunodeficiency virus. F Acquir Immune Defic Syndr 1992;5:1069-74.

27 Fekrat S, Dunn JP, Lee D, et al. Cytomegalovirus retinitis in HIV-infected patients with elevated CD4+ counts. Arch Ophthalmol 1995;113:18.

28 Freeman WR, Chen A, Henderly DE, et al. Prevalence and significance of acquired immunodeficiency syndromerelated retinal microvasculopathy. Am f Ophthalmol 1989; 107:229-35.

29 Whittle H, Egboga A, Todd J, et al. Clinical and laboratory predictors of survival in Gambian patients with symptopredictors of survival in Gambian patients with symp
matic HIV-1 or HIV-2 infection. AIDS 1992,6:685-9.

30 Kamanfu G, Mlika-Cabanne N, Girard PM, et al. Pulmonary complications of human immunodficiency Pulmonary complications of human immunodficiency
virus infection in Bujumbura, Burundi. Am Rev Respir Dis virus infection in 